\title{
Optimal Allocation of a Hybrid Wind Energy-Fuel Cell System Using Different Optimization Techniques in the Egyptian Distribution Network
}

\author{
Adel A. Abou El-Ela, Sohir M. Allam, Nermine K. Shehata* \\ Department of Electrical Engineering, Faculty of Engineering, Menoufia University, Shebin El-Kom, Egypt \\ Email: ^nerminekamel2016@yahoo.com
}

How to cite this paper: El-Ela, A.A.A., Allam, S.M. and Shehata, N.K. (2021) Optimal Allocation of a Hybrid Wind Energy-Fuel Cell System Using Different Optimization Techniques in the Egyptian Distribution Network. Energy and Power Engineering, 13, 17-40.

https://doi.org/10.4236/epe.2021.131002

Received: November 19, 2020

Accepted: January 12, 2021

Published: January 15, 2021

Copyright $\odot 2021$ by author(s) and Scientific Research Publishing Inc. This work is licensed under the Creative Commons Attribution International License (CC BY 4.0).

http://creativecommons.org/licenses/by/4.0/ (c) (i) Open Access

\begin{abstract}
This paper presents an optimal proposed allocating procedure for hybrid wind energy combined with proton exchange membrane fuel cell (WE/PEMFC) system to improve the operation performance of the electrical distribution system (EDS). Egypt has an excellent wind regime with wind speeds of about 10 $\mathrm{m} / \mathrm{s}$ at many areas. The disadvantage of wind energy is its seasonal variations. So, if wind power is to supply a significant portion of the demand, either backup power or electrical energy storage (EES) system is needed to ensure that loads will be supplied in reliable way. So, the hybrid WE/PEMFC system is designed to completely supply a part of the Egyptian distribution system, in attempt to isolate it from the grid. However, the optimal allocation of the hybrid units is obtained, in order to enhance their benefits in the distribution networks. The critical buses that are necessary to install the hybrid WE/ PEMFC system, are chosen using sensitivity analysis. Then, the binary Crow search algorithm (BCSA), discrete Jaya algorithm (DJA) and binary particle swarm optimization (BPSO) techniques are proposed to determine the optimal operation of power systems using single and multi-objective functions (SOF/MOF). Then, the results of the three optimization techniques are compared with each other. Three sensitivity factors are employed in this paper, which are voltage sensitivity factor (VSF), active losses sensitivity factor (ALSF) and reactive losses sensitivity factor (RLSF). The effects of the sensitivity factors (SFs) on the SOF/MOF are studied. The improvement of voltage profile and minimizing active and reactive power losses of the EDS are considered as objective functions. Backward/forward sweep (BFS) method is used for the load flow calculations. The system load demand is predicted up to year 2022 for Mersi-Matrouh City as a part of Egyptian distribution network, and the design of the hybrid WE/PEMFC system is applied. The PEMFC system is de-
\end{abstract}


signed considering simplified mathematical expressions. The economics of operation of both WE and PEMFC system are also presented. The results prove the capability of the proposed procedure to find the optimal allocation for the hybrid WE/PEMFC system to improve the system voltage profile and to minimize both active and reactive power losses for the EDS of Mersi-Matrough City.

\section{Keywords}

Wind Energy System, Proton Exchange Membrane Fuel Cell, Binary Crow Search Algorithm, Discrete Jaya Algorithm, Binary Particle Swarm Optimization Technique

\section{Introduction}

Distributed generations (DGs) consider an important issue for the electric utilities as DGs relieve capacity constraints on the generation, transmission and distribution systems and obviate the need to build new facilities [1]. The increasing penetration of DGs added to the distribution power system create new challenges, which can be classified into three main categories as technical, commercial and regulatory [2]. On the other hand, several benefits accrue by integrating DGs with electric utility, which can be classified into technical and economical. These benefits should be analyzed and quantified in order to increase the potential and value of DGs penetration. The major technical benefits are standby capacity, reliability, security and power quality, environmental and health concern. While, the economic benefits are reduced as costs associated with power losses, deferred investments for generation, transmission or distribution upgrades, lower operating costs due to peak shaving and reduced land use for generation [3] [4] [5], in recent years, the integration of the DGs into distribution networks has reached high penetration levels. The proper location and size of the DGs enhance their benefits in the distribution networks. DGs can be powered from either conventional or renewable fuel. In Egypt, wind energy (WE) is considered one of the most promising renewable energy (RE) source as it is renewable, plentiful, clean, and uses little land [6]. Egypt has an excellent wind regime with wind speeds of about $10 \mathrm{~m} / \mathrm{s}$ at Gulf of Suez coast. While, the large desert regions both to the east and the west of the Nile River, as well as parts of Sinai, have average annual wind speeds of $7-8 \mathrm{~m} / \mathrm{s}$ [7]. The disadvantage of WE is its seasonal variations. If wind power is to supply a significant portion of the demand, either backup power or electrical energy storage (EES) system is needed to ensure that loads will be supplied in reliable way [8] [9]. Recently greater focus has been placed on the use of new EES technologies such as fuel cell (FC), which depend on Hydrogen $\left(\mathrm{H}_{2}\right)$ as a fuel [10] [11] [12]. The electric distribution system (EDS) of Mersi-Mtrouh City as a part of the Egyptian distribution network can be supplied completely from wind farm combined with proton exchange membrane fuel cell (PEMFC) system, in an attempt to isolate it from the grid. The surplus power 
generated from the wind farm can be used to produce $\mathrm{H}_{2}$ from the electrolysis of water in an electrolyzer, $\mathrm{H}_{2}$ can be stored in $\mathrm{H}_{2}$ tanks and converted to electrical energy through the PEMFC, for power generation at deficit times [13]. In the literature, the hybrid power systems are discussed, for example, a hybrid photovoltaic fuel-cell generation system employing an electrolyzer for $\mathrm{H}_{2}$ generation and battery for storage purpose is designed and simulated in [14], power estimation model wind-hydrogen-fuel-cell-inverter system is presented in [15], photovoltaic/hydrogen/battery hybrid system is simulated in [16], the simulation results of a grid dependent hybrid system integrating a FC, photovoltaic(PV) and wind for distributed energy applications are shown in [17], in [18] a hybrid system consists of solar photovoltaic system and fuel cell system is used to supply the required electricity to a single phase load with the help of Pulse Width Modulation Voltage Source Inverter, a stand-alone hybrid microgrid consisting of wind turbines, photovoltaic arrays and storage battery banks is developed for use in an area in China [19], a method for optimal sizing of an off-grid hybrid micro-grid system in order to achieve a certain load demand is discussed in [20]. However, various algorithms have been used to solve the DGs placement problem such as fuzzy-genetic algorithm [21], genetic algorithm [22], firefly algorithm [23], batinspired algorithm, particle swarm optimization technique [24], ant colony [25], and simulated annealing [26] [27] [28]. In this paper, a hybrid wind energy and proton exchange membrane fuel cell system (WE/PEMFC) is designed for supplying a part of the Egyptian distribution network in a reliable way. This system is dependent on WE as a RE source and PEMFC as the EES. The system load demand is predicted up to year 2022 for Mersi-Matrouh City, and the design of the hybrid WE/PEMFC system is applied. The optimal allocation of inserting this hybrid system in the EDS of Meri-Matrouh City is presented by a two-stage procedure. In the first stage, the sensitivity analysis using three sensitivity factors (SFs) is employed to select the candidate buses for locating the hybrid system. In the second stage, the binary Crow search algorithm (BCSA), discrete Jaya algorithm (DJA) and binary particle Swarm optimization (BPSO) techniques are investigated to find the optimal allocation of the hybrid system. Multi system constraints will be considered to achieve the suggested single and multi-objective function (SOF/MOF). This paper consists of five subsections; Section 1 is the introduction, in Section 2 the proposed procedure for optimal allocation of the hybrid system is discussed, the SFs is illustrated, SOF/MOF and system constraints are discussed, the backward/forward sweep (BFS) method used in load flow calculation is illustrated and a brief description of the three optimization techniques used. Section 3 discusses the design and economics of the wind farm and the PEMFC system. Section 4 is the application and Section 5 is conclusion.

\section{Proposed Optimal Allocation of Hybrid WE/PEMFC System Using Parallel Sensitivity Factors}

This paper proposes an efficient optimization procedure based on three SFs pa- 
rallel with three different optimization techniques. First, the SFs will be used to select the candidate system buses for the installation of the hybrid WE/PEMFC system to reduce the search space of the optimization techniques. Second, the three different optimization techniques BCSA, DJA and BPSO are applied to find the optimal allocation of the hybrid WE/PEMFC system by achieving SOF/MOF. Third, the obtained results are compared with each other. The objective functions aim to minimize total active and reactive power losses and to improve voltage profile.

\subsection{Sensitivity Analysis}

Voltage sensitivity factor (VSF), active losses sensitivity factor (ALSF) and reactive active losses sensitivity factor (RLSF) are presented in this paper to rank the system buses according to their severity, to detect the candidate system buses that will need to install the hybrid WE/PEMFC system.

- VSF is represented by the ratio of the magnitude of the base case voltage to the minimum limit of voltage $(0.95 \mathrm{pu})$ as follow [29]:

$$
\mathrm{VSF}=\left|V_{B}\right| / 0.95
$$

The active power losses (APLs) of the distribution line connecting between buses $p$ and $q$ can be formulated as follow:

$$
P_{p q}=\frac{P^{2}+Q^{2}}{V_{q}^{2}} \cdot R_{p q}
$$

where; $P$ is the total effective active power supplied beyond the bus $q, Q$ is the total effective reactive power supplied beyond the bus $q, R_{p q}$ is the resistance of the distribution line connecting between buses $p$ and $q$ and $V_{q}$ is the voltage at bus $q$.

- ALSF can be written as:

$$
\mathrm{ALSF}=\frac{\partial P_{p q}}{\partial P}=\left(2 * P * R_{p q}\right) / V_{q}^{2}
$$

The reactive power losses (RPLs) of the distribution line connecting between buses $p$ and $q$ can be formulated as follows:

$$
Q_{p q}=\frac{P^{2}+Q^{2}}{V_{q}^{2}} \cdot X_{p q}
$$

where; $X_{p q}$ is the reactance of the distribution line connecting between buses $p$ and $q$.

- RLSF can be written as:

$$
\mathrm{RLSF}=\frac{\partial Q_{p q}}{\partial P}=\left(2 * P * X_{p q}\right) / V_{q}^{2}
$$

The system buses that have the smallest VSF positive values are considered as the candidate buses that need to install the hybrid system, and will be placed at the top of the VSF list. While, the buses that have the largest ALSF and RLSF positive values are considered as the candidate buses that need to install the hy- 
brid system, where these buses will be placed at the top of the ALSF list and RLSF list, respectively. The candidate system buses for the installation of the hybrid system based on the VSF list, ALSF list and RLSF list are inserted as control variables in the optimization algorithms.

\subsection{Single and Multi-Objective Functions}

The proposed optimization techniques aim to determine the best allocation of the hybrid WE/PEMFC system in the EDS of Mersi-Matrouh City, by minimizing bus voltage index $(B V I)$, active losses index $(A L I)$ and reactive losses index $(R L I)$ as $S O F$ and $M O F$

\subsubsection{Single Objective Function (SOF)}

By taking the ratio of a measure of an attribute with and without the hybrid WE/PEMFC system at the same loading conditions, some indices can be derived for any attribute as follows:

1) Minimizing $B V I$ :

$$
F_{1}=\operatorname{Min} B V I \%=\left|V_{B}-V_{B, H}\right| / V_{B}
$$

where; $V_{B}$ and $V_{B, H}$ are the system bus voltage without and with the hybrid WE/ PEMFC system, respectively.

2) Minimizing $A L I$ :

$$
F_{2}=\operatorname{Min} A L I \%=\left(A L_{S K, H} / T A L_{s y s}\right)
$$

where, $A L_{s k, H}$ is the APLs of section $k$ of the EDS with considering the hybrid WE/PEMFC system. TAL $L_{s y s}$ is the total active power losses (TAPLs) of the EDS without considering the hybrid WE/PEMFC system.

3) Minimizing $R L I$ :

$$
F_{3}=\operatorname{MinRLI\% }=\left(R L_{S K, H} / T R L_{s y s}\right)
$$

where, $R L_{s k, H}$ is the RPLs of section $k$ of the EDS with considering the hybrid WE/PEMFC system. TRL $L_{s y s}$ is the total reactive power losses (TRPLs) of the EDS without considering the hybrid WE/PEMFC system.

\subsubsection{Multi-Objective Function (MOF)}

The $M O F$ is formulated as:

$$
\begin{gathered}
F=\operatorname{MinMOF}=W_{1} \cdot F_{1}+W_{2} \cdot F_{2}+W_{3} \cdot F_{3} \\
\text { with } 0 \leq W_{i} \leq 1, \sum_{i=1}^{3} W_{i}=1
\end{gathered}
$$

where; $W_{1}, W_{2}$ and $W_{3}$ are the weighting factors (WFs) for $B V I \%, A L I \%$ and $R L I \%$, respectively. And can be obtained by trial and error.

\subsubsection{System constraints}

The $S O F / M O F$ are subjected to the following system constraints:

1) System bus voltage constraints

The voltage at each bus $V_{B}$ must be within their minimum and maximum lim- 
its ( $V_{B M I N}$ and $\left.V_{B M A X}\right)$ as:

$$
V_{B M I N} \leq V_{B} \leq V_{B M A X}
$$

2) Total number of hybrid units (DGs) constraint

The number of DGs $\left(N_{D G s}\right)$ must be less than or equal to the maximum permissible number of DGs $\left(N_{D G \max }\right)$.

$$
N_{D G s} \leq N_{D G \max }
$$

3) Active power flow constraint

The active power flow in the $k^{\text {th }}$ line $\left(A F^{K}\right)$ should be less than or equal to the maximum permissible active power flow $\left(A F^{\text {Kmax }}\right)$.

$$
A F^{K} \leq A F^{K \max }
$$

4) Reactive power flow constraint

The reactive power flow in line $k\left(R F^{K}\right)$ should be less than or equal to the maximum permissible reactive power flow $\left(R F^{\text {Kmax }}\right)$.

$$
R F^{K} \leq R F^{\text {Kmax }}
$$

\subsection{Backward-Forward Sweep (BFS) Load Flow Method}

The BFS method is one of the most common ways used for load flow calculation of distribution system as it is fast, simple, robust convergence and low memory requirement for processing with efficiencies and solution accuracies computational [30]. The BFS algorithm involves three iterative basic steps. The three steps are named as the nodal current calculation, the backward sweep and the forward sweep. These steps based on Kirchoff's current law (KCL) and Kirchoff's voltage law $(\mathrm{KVL})$

\subsection{Optimization Techniques}

In this paper, three optimization techniques are used to determine the best allocation of the hybrid WE/PEMFC system in the EDS of Mersi-Matrouh City. These optimization techniques are the BCSA, DJA and BPSO.

\subsubsection{Binary Crow Search Algorithm (BCSA)}

CSA is a nature-inspired algorithm presented by Askarzadeh in 2016 [31], CSA mimics the behavior of Crow birds and their social interaction. Crows watch other birds and observe where they hide their food. Once the other birds leave, they steal their food. The Crows use their intelligence to hide their excess food in a hideout spot and restore this food when they need. If a Crow discovers another one is going after it, it will try to deceive that Crow and will go to another position. CSA can be implemented as follow [32] [33]:

- Initialization: the Crow in the folk represents a solution to the problem.

- If there is a solution space with dimension $d$ has a Crow folk of $N$ Crows, the position $X$ of Crow $i$ at iteration $t$ can be expressed by the vector:

$$
X^{i, t}=\left[\begin{array}{llll}
X_{1}^{i, t} & X_{2}^{i, t} & X_{3}^{i, t} \cdots X_{d}^{i, t}
\end{array}\right]
$$


- Each Crow has a memory to store the best position of its stored food source.

- The memory $M$ of all Crows at iteration $t$ for dimension $d$ are initialized as follows:

$$
M=\left[\begin{array}{ccc}
m_{11}^{t} & \cdots & m_{1 d}^{t} \\
\vdots & \ddots & \vdots \\
m_{N 1}^{t} & \cdots & m_{N d}^{t}
\end{array}\right]
$$

- Solution evaluation (fitness): each solution in the population is evaluated using objective function.

- Position update: to update the position of the Crow between Crows $J$ and $i$, there are two cases:

Case 1: Crow $J$ does not recognize that Crow $i$ is going after it. Hence, Crow $i$ will get close the storing place of Crow $J$.

Case 2: Crow $J$ recognizes that Crow $i$ is going after it, so, it will move to another position to deceive Crow $i$ and to save its food.

$$
X^{i, t+1}= \begin{cases}X^{i, t}+r_{a i} \times F l^{i, t} \times\left(m^{j, t}-X^{i, t}\right) & r_{J} \geq A P^{J, t} \\ \text { random position } & \text { otherwise }\end{cases}
$$

where; $A P$ is the awareness factor and $F^{F t}$ is the flight length of Crow $i$ at iteration $t$. The main reasons of using CSA are for easy implementation, few control parameters to adjust, fast convergence speed and high efficiency. To further enhance the performance of the classical CSA, BCSA is proposed. At each position, the solution considers values " 0 " or " 1 ", where, "0" represents the solution that is not selected and " 1 " represents the solution that is selected.

\subsubsection{Discrete Jaya Algorithm (DJA)}

Jaya algorithm is one of the newly developed population based optimization method, which was proposed by Rao in 2016 [34]. The Jaya algorithm is simple in putting into use as a solution is updated only in a single phase by employing a single equation. The basic concept of the Jaya is based on the best and worst solution of objective function. Jaya needs only the common control parameters and does not need any algorithm clearly stated control parameters [35]. A new DJA is the optimization algorithm used here for finding the optimal allocation of the hybrid system problem. In this algorithm, the solution contains two phases, meanwhile the candidate locations are rounded about its real values and the number of candidate buses are determined by binary strategy. The number of the best locations, with their hybrid WE/PEMFC system, are updated by the DJA in each iterations. The algorithm is continued until the termination criterion is met.

\subsubsection{Binary Particle Swarm Optimization (BPSO) Technique}

The mechanics of PSO technique are inspired by the swarming of biological populations. In PSO technique, the particles change their positions with time [36]. The classical PSO is operated on real values, here the BPSO is proposed which is operated on $[0,1]$ values. 


\subsubsection{Proposed Allocation Procedure of Hybrid WE/PEMFC System}

The optimal allocation procedure is illustrated below:

1) Input data: input the number of system buses, load demand at each bus, transmission lines' impedance, control parameters of the used optimization technique.

2) Perform the initial load flow analysis using the BFS method to calculate the $\mathrm{SFs}$, the VSF are arranged in ascending order for all buses of the study system. While, the ALSF and RLSF are arranged in descending order for all system lines. Thus, the candidate buses for inserting the hybrid WE/PEMFC system can be determined.

3) Implement one of the three proposed optimization techniques.

4) Perform the load flow analysis using BFS method again to obtain the voltage at each system bus, APLs and RPLs.

5) Calculate the fitness function of $S O F / M O F$ for each proposed solution.

6) Repeat until the maximum number of iterations is reached or the solution is obtained.

7) The previous steps will be repeated with the other two proposed optimization techniques. Then the obtained results are compared with each other.

\section{Optimal hybrid WE/PEMFC System Approach}

A hybrid WE/PEMFC system is designed, in which the surplus power from the wind farm is used to generate $\mathrm{H}_{2}$ through the water electrolyzer, the $\mathrm{H}_{2}$ will be stored in the $\mathrm{H}_{2}$ tank, then, $\mathrm{H}_{2}$ will be used to generate the required electricity through the PEMFC to supply loads at deficit times, as so, the loads will be supplied in reliable way, as will be illustrated in the following sections.

\subsection{Design of the Wind Turbines Energy}

Different wind turbines (WTs) which are suitable for supplying the EDS were optimized considering both technical and economical points of view [37]. The generation model and economics of the WT are discussed as follow:

\subsubsection{Generation Model of the Wind Energy}

The average output of WT is given as follows [38]:

$$
P_{\text {ave }}=\frac{\exp \left[-\left(V_{\text {cin }} / C\right)^{K}\right]-\exp \left[-\left(V_{r} / C\right)^{K}\right]}{\left[\left(V_{r} / C\right)^{K}-\left(V_{\text {cin }} / C\right)^{K}\right]-\exp \left[-\left(V_{\text {cout }} / C\right)^{K}\right]} \cdot P_{r}
$$

where; $P_{a v e}$ is the average power, $P_{r}$ is the rated power, $V_{c i n}$ is the cut-in wind speed, $V_{r}$ is the rated wind speed and $V_{\text {cout }}$ is the cut-out wind speed, $C$ and $K$ are the scale and shape parameters of Weibull probability distribution function, respectively. The average output of the wind farm is given as follows:

$$
P_{A, W F}=P_{a v e} \times N_{D G s}
$$

\subsubsection{The Proposed Economical Model of the Wind Farm}

The unit energy cost $\left(U_{E . C}\right)$ of WT is calculated dependent on the value of both 
the annual capital cost (AC.C) and the annual operation cost (AO.C). The $U_{E . C}$ is given as:

$$
U_{E . C}=(A C . C+A O . C) / A E_{W T} \$ / \text { year }
$$

where; $A E_{W T}$ is the energy output of WT per year. The total unit energy cost of the wind farm $\left(U_{W F}\right)$ is given as:

$$
U_{W F}=U_{E . C} \times N_{D G s}+P_{\text {Land }} \$ / \text { year }
$$

where; $P_{\text {Land }}$ is the price of land used for the installation of the wind farm.

\subsubsection{Produced Amount of $\mathrm{H}_{2}$ from the Wind Farm}

The amount of $\mathrm{H}_{2}$ that needs to be supplied the $\mathrm{FC}$ to produce one $\mathrm{kWh}$ of electricity from the surplus power of wind farm can be obtained as follow [39]:

$$
H_{2}^{\text {Amount }}=\left(2 * n_{\text {rate }} * 3600\right) /\left(\left(237.2 n_{\text {rate }}\right) * 10^{-3}\right) \text { gram } / \mathrm{kWh}
$$

where, $n_{\text {rate }}$ is the rate of flow of $\mathrm{H}_{2}$ into the cell in $(\mathrm{mol} / \mathrm{sec})$.

\subsection{Design of Proton Exchange Membrane Fuel Cell (PEMFC)}

In this paper, PEMFC is designed at low operating temperature between $\left[60^{\circ} \mathrm{C}\right.$ $\left.100^{\circ} \mathrm{C}\right]$ that has relatively high electrical efficiency between $[40 \%-50 \%]$. The design of PEMFC is performed by considering the voltage-current electrical characteristics of the PEMFC as shown in Figure 1. The maximum power is corresponding to the operation of PEMFC between 0.6 and 0.8 Volt per cell [40]. By fitting the V-I curve, the following equation can be obtained as [12]:

$$
V_{\text {cell }}=0.85-0.25 *(I / A)
$$

where, $V_{\text {cell, }} I$ and $A$ are the single cell voltage, the current and the single cell area, respectively. The stack of the PEMFC can be expressed as follow

$$
V_{\text {stack }}=(0.85-0.25 *(I / A)) * N
$$

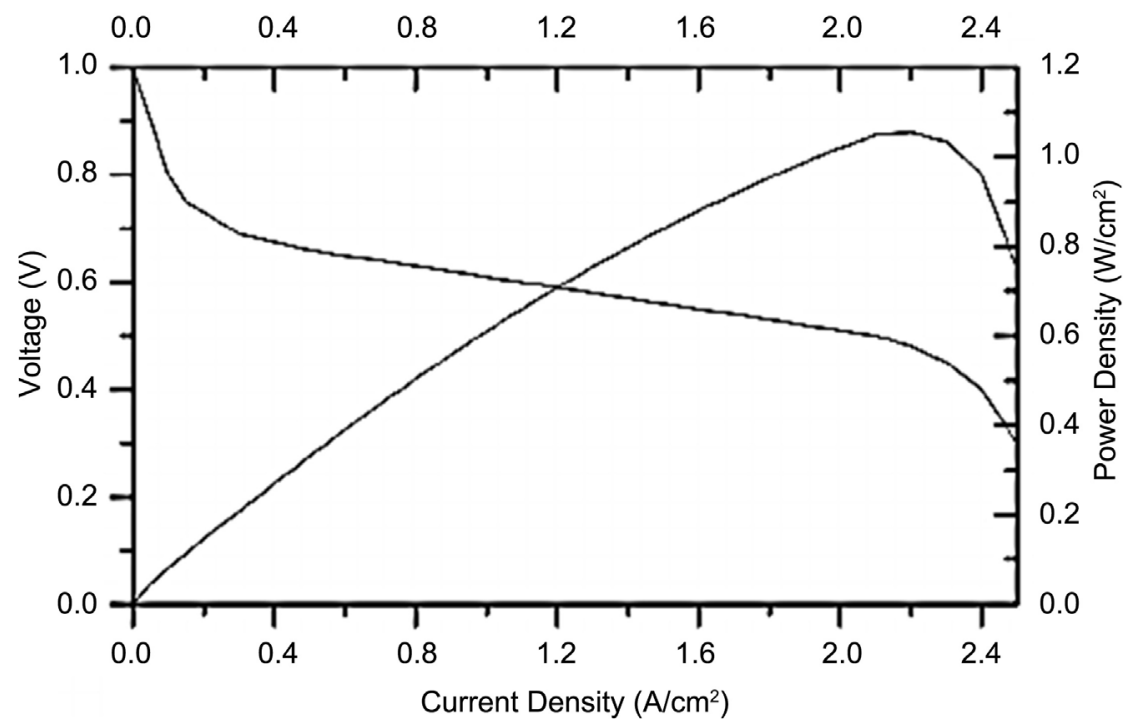

Figure 1. Voltage-current curve for a typical FC [12]. 


$$
P_{\text {stack }}=V_{\text {stack }} * I
$$

where; $V_{\text {stack }}, P_{\text {stack }}$ and $N$ are the stack voltage, the power of the stack and the number of stack series cells, respectively.

\subsubsection{Water Electrolyzer}

The electrolyzer size is determined by its production flow rate $\left(\mathrm{H}_{2}\right)$ as illustrated [41]:

$$
H_{2 \text { rate }}=\left(60 * E_{L} * n_{e} * g_{m}\right) /\left(U_{G} * V_{\text {cell }} * n_{\text {em }} * n_{m m}\right)
$$

where; $H_{2 r a t e}$ is the $\mathrm{H}_{2}$ flow rate, $E_{L}$ is the average electrical load in Wh/day, $n_{e}$ is the number of electrons per second for 1 ampere, $g_{m}$ is the molar mass of $\mathrm{H}_{2}$ in $\mathrm{g} / \mathrm{mol}, U_{f}$ is the utilization factor which takes $0.8, V_{\text {cell }}$ is the cell voltage, $n_{e m}$ is the number of electrons per each molecule of $\mathrm{H}_{2}$ and $n_{m m}$ is the number of molecules per $\mathrm{H}_{2}$ mol. The electrolyzer size can be calculated by dividing the total amount of $\mathrm{H}_{2}$ per year required from the PEMFC by the total windy hours per year as follow:

$$
E_{\text {Size }}=\left(H_{2 \text { rate }} * E_{L} * 365\right) / h_{\text {Wind }}
$$

where; $h_{\text {wind }}$ is the total windy hours per year.

\subsubsection{Hydrogen Tank}

The volume of the $\mathrm{H}_{2}$ tank can be determined from the ideal gas low as follow [41]:

$$
V_{T}=(n * R * T) / P
$$

where; $V_{T}$ is the volume of the $\mathrm{H}_{2}$ tank, $n$ is the number of moles, $R$ is the gas constant, $T$ is the temperature in Kelvin and $P$ is pressure.

\subsubsection{Calculation of Unit Energy Cost of the Designed PEMFC System}

The annual cost (AC) of PEMFC system can be calculated as follow:

$$
A C=C_{C}+C_{\text {Tank }}+C_{\text {Electro }}+C_{\text {O\&M }}+\left(C_{\text {run }} /(1+i)^{Y}\right)-\left(S_{v} /(1+i)^{Y}\right)
$$

where, $C_{O \& M}$ is the annual operating and maintenance costs of the PEMFC system, $Y$ is the life time of the PEMFC system, $C_{C}$ is the capital cost, $C_{\text {Tank }}$ is the annual cost of $\mathrm{H}_{2}$ tank, $C_{\text {Electro }}$ is the annual cost of the electrolyzer, $S_{V}$ is the annual salvage value, $C_{\text {run }}$ is the annual running cost and $i$ is the interest rate. The unit energy cost $\left(C_{O E}\right)$ can be calculated by dividing the $A C$ of the PEMFC system by the total generated energy, during the system cycle as follow:

$$
C_{O E}=A C / E^{e}
$$

where, $E^{e}$ is the electrical generated energy in kWh.

\section{Application}

The optimal hybrid WE/PEMFC system approach discussed in Section 3 is applied for supplying the EDS of Mersi-Matrouh City, in attempt to isolate it from the grid. Also, the proposed optimal allocation procedure of the hybrid WE/ 
PEMFC system in the EDS of Mersi-Matrouh City discussed in Section 2 is applied.

\subsection{Design of Hybrid WE/PEMFC System for Mersi-Matrouh City}

Load forecasting of the electrical peak load demand of Mersi-Matrouh City is obtained up to year 2022 [42], using the historical data shown in Table 1. The peak load demand of Mersi-Matrouh City in year 2022 is equal to 8655.3 MW. The proposed models in Section 3 are used to estimate the optimal technical and economical wind energy which is $3000 \mathrm{~kW}$-WT for Mersi-Matrouh City by considering Equations (14)-(17). Figure 2 shows the EDS of Mersi-Matrouh City up to year 2022. Figure 3 gives the average daily power supplied to the load at Mersi-Matrouh City in year 2022. The characteristics of $3000 \mathrm{~kW}$-WT (E101/3000) model is used to evaluate the output wind energy $\left(E_{W T}\right)$. The hybrid WE/PEMFC system consists of $45 \times 3000 \mathrm{~kW}$-WT, which gives 239,611.5 MWh per year. The wind farm gives surplus power of about 427.999 MWh which is used to produce $7,275,983$ grams of $\mathrm{H}_{2}$ through an electrolyzer, where, QLC-180 PEM electrolyzer cell stack is used [43]. PEMFC can produce electric energy of about 107.88 MWh that can be used to supply the deficit power of $67.6 \mathrm{MWh}$ at the time of shortage power. So, this EDS can be isolated from the grid. These values are illustrated in Table 2.

The proposed economical model in section 3.1.2 is applied to calculate the $U_{E . C}$ and $U_{W F}$ up to year 2022, as shown in Table 3. The proposed economical model of wind farm is performed according to the following assumptions [44]:

- The capital cost (C.C) is assumed as $800 \$ / \mathrm{kW}$.

- The annual operation cost (AO.C) is assumed as $2.0 \$ / \mathrm{kWh}$.

Table 1. Historical electrical peak load data of Mersi-Matrouh City from 2005 to 2019.

\begin{tabular}{ccccccccc}
\hline Year & 2005 & 2006 & 2007 & 2008 & 2009 & 2010 & 2011 & 2012 \\
\hline$P_{D}(\mathrm{MW})$ & 3102.6 & 3319 & 3552 & 3800 & 4066 & 4351 & 4656 & 4982 \\
Year & 2013 & 2014 & 2015 & 2016 & 2017 & 2018 & 2019 & - \\
$P_{D}(\mathrm{MW})$ & 5331 & 5704 & 6103 & 6530 & 6987 & 7477 & 8000 & -
\end{tabular}

Table 2. Energy generation of the hybrid WE/PEMFC system.

\begin{tabular}{cc}
\hline Wind Farm Surplus Power (MWh) & 427.999 \\
Grams of $\mathrm{H}_{2}$ Produced From the Surplus Power $(\mathrm{g})$ & $7,275,983$ \\
Produced Electricity From PEMFC System (MWh) & 107.88 \\
Wind Farm Deficit Power (MWh) & 67.6 \\
\hline
\end{tabular}

Table 3. Capital cost (C.C), the annual capital cost (AC.C), the annual operating cost ( $A O . C)$, the unit energy cost $\left(U_{E . C}\right)$ and the total unit energy cost of wind farm.

\begin{tabular}{ccccc}
\hline$C . C(\$)$ & $A C . C(\$)$ & $A O . C(\$)$ & $U_{E . C}(\Phi / \mathrm{kWh})$ & $U_{W F}(\Phi / \mathrm{kWh})$ \\
\hline $2,400,000$ & 321,120 & 106,494 & 8 & 8.035 \\
\hline
\end{tabular}




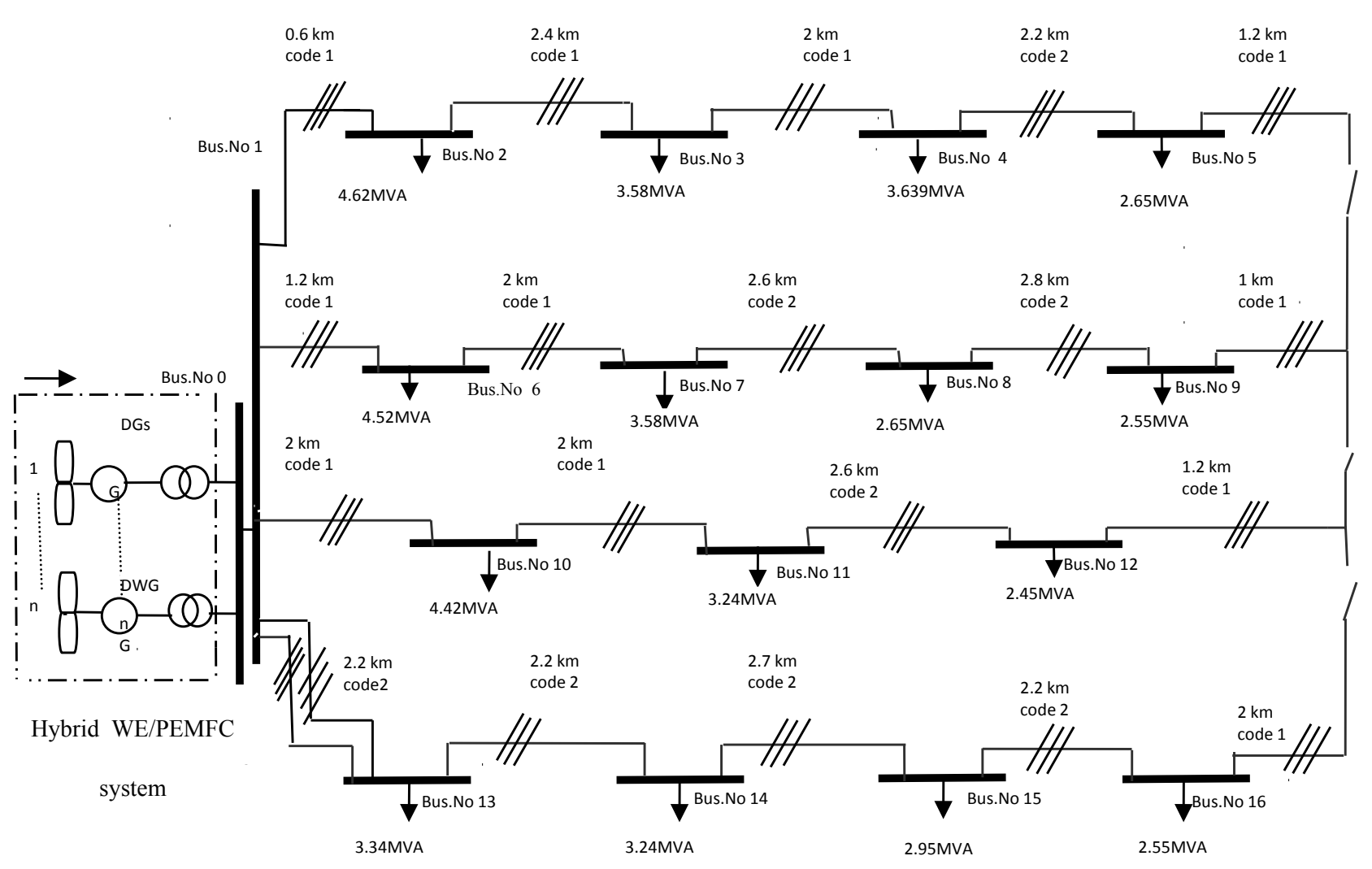

Line code $1=0.1683+\mathrm{j} 0.3248 \Omega / \mathrm{Km}$ Line code $2=0.5448+\mathrm{j} 0.4292 \Omega / \mathrm{Km}$

Figure 2. EDS of Mersi-Matrouh City up to 2022.

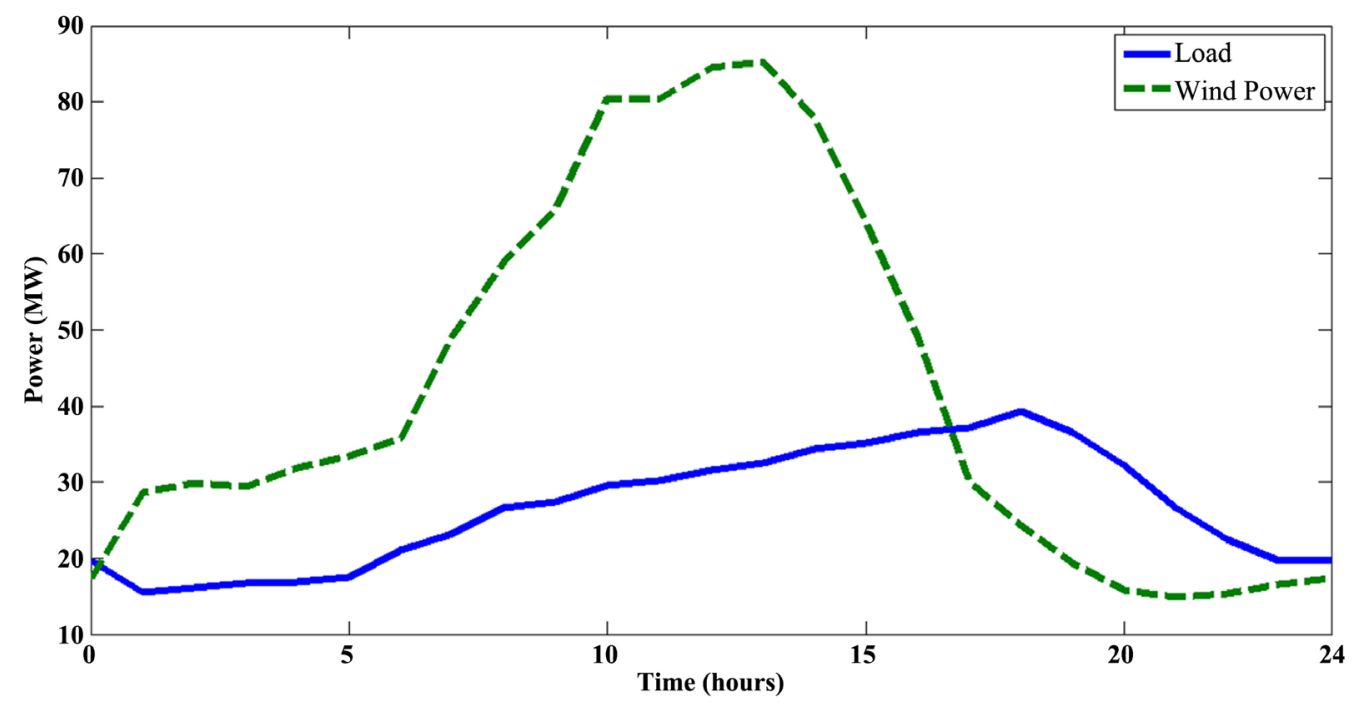

Figure 3. Wind farm average daily power supplied for Mersi-Matrough City up to year 2022 [38].

- The interest rate is assumed as $12 \%$, while, the life-time is assumed as 20 years.

- The price of land used for wind farm is equal to $40,060 \$$ per year.

PEMFC system is designed as illustrated in Section 3.2 and the design para- 
meters of the PEMFC stacks are illustrated in Table 4. The design of the PEMFC stack is performed under the following considerations; FC running time is 3000 hrs/year, $V_{\text {cell }}=0.6 \mathrm{~V}, V_{\text {stack }}=72 \mathrm{~V}$, electorlyzer efficiency is $85 \%$ and PEMFC efficiency is $45 \%$ as Equations (19)-(24).

The $C_{O E}$ of the designed PEMFC system is also calculated including $\mathrm{H}_{2}$ tank cost and electrolyzer cost as shown in Table 5 and performed under the following assumptions, as Equation (26):

- The $C_{C}$ of the PEMFC system is $4400 \$ / \mathrm{kW}$.

- $C_{O \& M}$ is assumed as $0.035 \$ / \mathrm{kW}$.

- $i$ is assumed as $5 \%$.

- $C_{r u n}$ and $S_{V}$ are assumed as $9 \%$ of the $C_{C}$.

To reduce the storage volume of the $\mathrm{H}_{2}$ gas, the pressure needs to increase. In this paper, the type four (type IV) tank is used [45]. The specification of type IV hydrogen tank is shown in the Appendix. The limits of voltage magnitude are taken between 0.95 and 1.05 p.u, the maximum permissible number of DG units is taken as 16 unit, the maximum permissible active power flow is $7.5 \mathrm{MW}$ for line code 1 and $4.9 \mathrm{MW}$. While, the maximum permissible reactive power flow are 3.63 MVAR for line code1 and 2.37 MVAR for line code 2.

\subsection{Results and Discussions of Proposed Procedures}

The proposed procedures are applied to the EDS of Mersi-Matrouh City in order to solve the optimal allocation of hybrid WE/PEMFC system problem by achieving the $\mathrm{SOF} / \mathrm{MOF}$ and satisfying system constraints. Optimal allocating problem is solved with and without considering the SFs. Then these results are compared with each other.

\subsubsection{Optimal Candidate Buses Using Sensitivity Factors (SFs)}

Figure 3 includes four feeders, each feeder consists of four buses and five connecting cables, except the third feeder which includes only three buses and four connecting cables. This EDS is completely supplied from hybrid WE/PEMFC system that depends on WT which has rated of $3000 \mathrm{~kW}$ for each turbine combined with PEMFC stacks which has rated of $5 \mathrm{~kW}$ for each unit. Figure 4 and Figure 5 show the values of VSF, ALSF and RLSF, respectively. According to system buses ordering in these figures, the first seven buses of the bus-number are considered as the candidate buses for allocating the hybrid WE/PEMFC system.

Table 4. Design parameters of the PEMFC system for Mersi-Matrouh City.

\begin{tabular}{ccccccc}
\hline$P_{\text {stack }}(\mathrm{W})$ & $V_{\text {stack }}(\mathrm{V})$ & $I(\mathrm{~A})$ & $V_{\text {cell }}(\mathrm{V})$ & $\mathrm{H}_{2}$ Tank Type & No.Stacks & Electrolyzer Type \\
\hline 5000 & 72 & 69.44 & 0.6 & Type IV, 200 Liter, 500 bar & 8 & QLC-180 \\
\hline
\end{tabular}

Table 5. Economics of the PEMFC system for Mersi-Matrouh City.

\begin{tabular}{ccc}
\hline$C_{C}(\$)$ & $C_{O \& M}(\$)$ & $C_{O E}(\$ / \mathrm{kWh})$ \\
\hline $32,742.85$ & 4200 & 0.27 \\
\hline
\end{tabular}




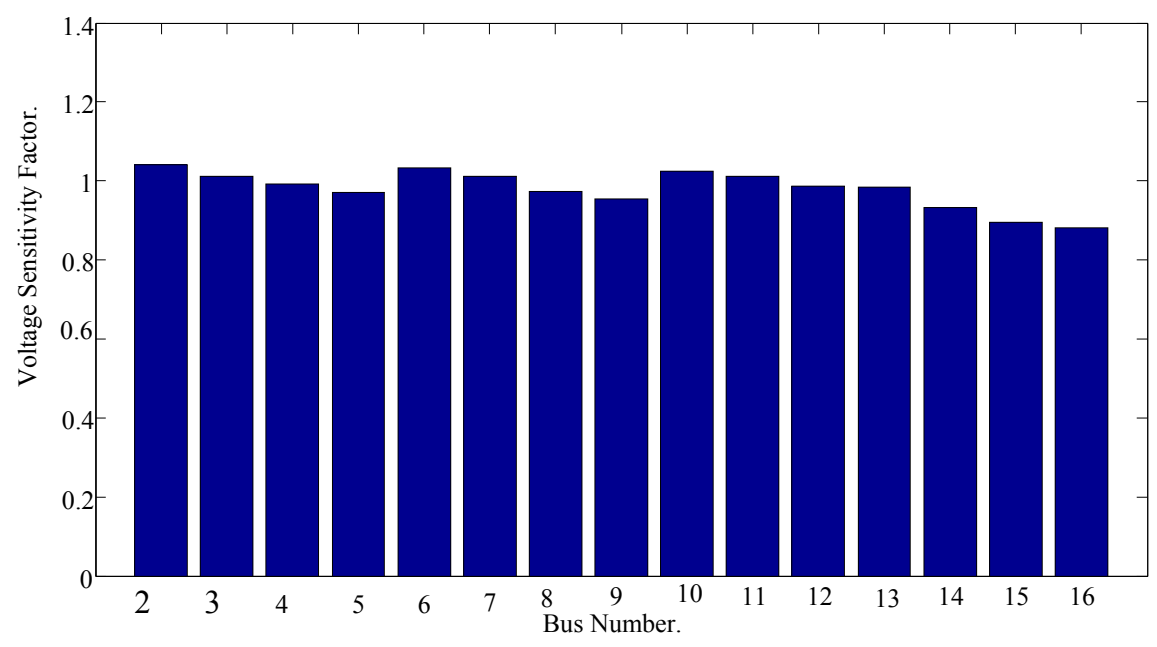

Figure 4. The values of VSF for each system bus.

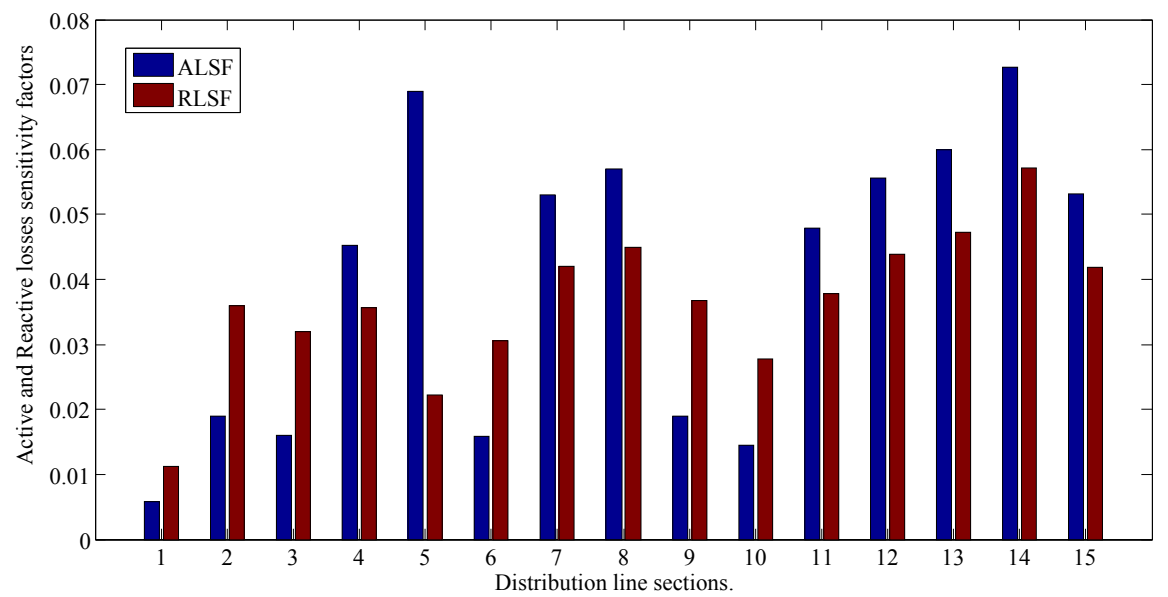

Figure 5. The values of both ALSF and RLSF for each transmission line section.

\subsubsection{Minimizing the SOF without and with Considering Sensitivity Factors (SFs)}

Minimizing the SOF is performed using the three proposed optimization techniques without and with considering the SFs. Table 6 and Table 7 show the optimal allocating for the hybrid system, and the corresponding number of the hybrid units (DGs) using BCSA, DJA and BPSO techniques in year 2022 without and with considering SFs, respectively. While, Table 8 shows a comparison among the fitness values using the three proposed optimization techniques with and without the hybrid system for the SOF without and with considering the SFs in year 2022 .

\subsubsection{Minimizing of $F_{1}$ as a SOF}

Table 8 illustrates the improvement in $F_{1}$ without and with considering the SFs using the three proposed optimization techniques in year 2022. From Table 8, the best technique without considering the SFs is DJA that gives improvement in bus voltage about $75 \%$, then, BCSA improves the bus voltage by $72.3 \%$, finally BPSO technique improves the bus voltage by $71.5 \%$. Also, the best technique is 
Table 6. Sitting, sizing (S) in MW and corresponding number of DGs (N) using the three proposed optimization techniques without considering the SFs in year 2022 using SOFs.

\begin{tabular}{|c|c|c|c|c|c|c|c|c|c|c|c|c|c|c|c|c|c|c|}
\hline \multirow{3}{*}{ Bus. No } & \multicolumn{6}{|c|}{$\mathrm{F}_{1}$} & \multicolumn{6}{|c|}{$\mathrm{F}_{2}$} & \multicolumn{6}{|c|}{$\mathrm{F}_{3}$} \\
\hline & \multicolumn{2}{|c|}{ BCSA } & \multicolumn{2}{|c|}{ DJA } & \multicolumn{2}{|c|}{ BPSO } & \multicolumn{2}{|c|}{ BCSA } & \multicolumn{2}{|c|}{ DJA } & \multicolumn{2}{|c|}{ BPSO } & \multicolumn{2}{|c|}{ BCSA } & \multicolumn{2}{|c|}{ DJA } & \multicolumn{2}{|c|}{ BPSO } \\
\hline & S & $\mathrm{N}$ & S & $\mathrm{N}$ & $S$ & $\mathrm{~N}$ & S & $\mathrm{N}$ & $S$ & $\mathrm{~N}$ & $S$ & $\mathrm{~N}$ & S & $\mathrm{N}$ & $S$ & $\mathrm{~N}$ & $S$ & $\mathrm{~N}$ \\
\hline 2 & 2 & 4 & 5 & 9 & 5 & 9 & 2 & 4 & 7 & 12 & 6 & 10 & 2 & 4 & 7 & 12 & 6 & 10 \\
\hline 3 & 5 & 9 & 2 & 4 & 2 & 4 & 6 & 10 & 2 & 4 & 6 & 10 & 6 & 10 & 2 & 4 & 6 & 10 \\
\hline 4 & 2 & 4 & 2 & 4 & 3 & 5 & 2 & 4 & 3 & 5 & 3 & 5 & 2 & 4 & 3 & 5 & 3 & 5 \\
\hline 5 & 3 & 5 & 2 & 4 & 3 & 5 & 4 & 7 & 2 & 4 & 2 & 4 & 4 & 7 & 2 & 4 & 2 & 4 \\
\hline 6 & 5 & 9 & 4 & 7 & 3 & 5 & 7 & 12 & 6 & 10 & 5 & 9 & 7 & 12 & 6 & 10 & 5 & 9 \\
\hline 7 & 3 & 5 & 3 & 5 & 3 & 5 & 4 & 7 & 4 & 7 & 3 & 5 & 4 & 7 & 4 & 7 & 3 & 5 \\
\hline 8 & 2 & 4 & 2 & 4 & 3 & 5 & 2 & 4 & 2 & 4 & 4 & 7 & 2 & 4 & 2 & 4 & 4 & 7 \\
\hline 9 & 2 & 4 & 2 & 4 & 2 & 4 & 2 & 4 & 2 & 4 & 3 & 5 & 2 & 4 & 2 & 4 & 3 & 5 \\
\hline 10 & 2 & 4 & 1 & 2 & 2 & 4 & 2 & 4 & 2 & 4 & 4 & 7 & 2 & 4 & 2 & 4 & 4 & 7 \\
\hline 11 & 2 & 4 & 2 & 4 & 2 & 4 & 2 & 4 & 2 & 4 & 2 & 4 & 2 & 4 & 2 & 4 & 2 & 4 \\
\hline 12 & 2 & 4 & 3 & 5 & 2 & 4 & 3 & 5 & 4.9 & 9 & 3 & 5 & 3 & 5 & 4.9 & 9 & 3 & 5 \\
\hline 13 & 3 & 5 & 3 & 5 & 3 & 5 & 4 & 7 & 4.9 & 9 & 3 & 5 & 4 & 7 & 4.9 & 9 & 3 & 5 \\
\hline 14 & 2 & 4 & 2 & 4 & 2 & 4 & 3 & 5 & 2 & 4 & 4 & 7 & 3 & 5 & 2 & 4 & 4 & 7 \\
\hline 15 & 2 & 4 & 2 & 4 & 2 & 4 & 3 & 5 & 3 & 5 & 4 & 7 & 3 & 5 & 3 & 5 & 4 & 7 \\
\hline 16 & 2 & 4 & 2 & 4 & 2 & 4 & 3 & 5 & 3 & 5 & 2 & 4 & 3 & 5 & 3 & 5 & 2 & 4 \\
\hline
\end{tabular}

Table 7. Sitting, sizing (S) in MW and corresponding number of DGs (N) using BCSA, DJA and BPO technique with considering the SFs in year 2022 using SOFs.

\begin{tabular}{|c|c|c|c|c|c|c|c|c|c|c|c|c|c|c|c|c|c|c|}
\hline \multirow{3}{*}{ Bus. No } & \multicolumn{6}{|c|}{$\mathrm{F}_{1}$} & \multicolumn{6}{|c|}{$\mathrm{F}_{2}$} & \multicolumn{6}{|c|}{$\mathrm{F}_{3}$} \\
\hline & \multicolumn{2}{|c|}{ BCSA } & \multicolumn{2}{|c|}{ DJA } & \multicolumn{2}{|c|}{ BPSO } & \multicolumn{2}{|c|}{ BCSA } & \multicolumn{2}{|c|}{ DJA } & \multicolumn{2}{|c|}{ BPSO } & \multicolumn{2}{|c|}{ BCSA } & \multicolumn{2}{|c|}{ DJA } & \multicolumn{2}{|c|}{ BPSO } \\
\hline & S & $\mathrm{N}$ & $S$ & $\mathrm{~N}$ & $S$ & $\mathrm{~N}$ & S & $\mathrm{N}$ & $S$ & $\mathrm{~N}$ & $S$ & $\mathrm{~N}$ & $S$ & $\mathrm{~N}$ & $S$ & $\mathrm{~N}$ & $S$ & $\mathrm{~N}$ \\
\hline 2 & - & - & - & - & - & - & 2.9 & 5 & 2.9 & 5 & 2.9 & 5 & 2.9 & 5 & 2.9 & 5 & 2.9 & 5 \\
\hline 3 & - & - & - & - & - & - & 2.9 & 5 & 2.9 & 5 & 2.9 & 5 & 2.9 & 5 & 2.9 & 5 & 2.9 & 5 \\
\hline 4 & - & - & - & - & - & - & 2.7 & 5 & 2.7 & 5 & 2.7 & 5 & 2.7 & 5 & 2.7 & 5 & 2.7 & 5 \\
\hline 5 & 3 & 5 & 2 & 4 & 2 & 4 & 2.7 & 5 & 2.7 & 5 & 2.7 & 5 & 2.7 & 5 & 2.7 & 5 & 2.7 & 5 \\
\hline 6 & - & - & - & - & - & - & 4 & 7 & 2 & 4 & 4 & 7 & 4 & 7 & 2 & 4 & 4 & 7 \\
\hline 7 & - & - & - & - & - & - & 3.2 & 6 & 3.2 & 6 & 3.2 & 6 & 3.2 & 6 & 3.2 & 6 & 3.2 & 6 \\
\hline 8 & - & - & - & - & - & - & 3.3 & 6 & 3.3 & 6 & 3.3 & 6 & 3.3 & 6 & 3.3 & 6 & 3.3 & 6 \\
\hline 9 & 2 & 4 & 2 & 4 & 2 & 4 & 3.2 & 6 & 3.2 & 6 & 3.2 & 6 & 3.2 & 6 & 3.2 & 6 & 3.2 & 6 \\
\hline 10 & - & - & - & - & - & - & 2.9 & 5 & 2.9 & 5 & 2.9 & 5 & 2.9 & 5 & 2.9 & 5 & 2.9 & 5 \\
\hline 11 & - & - & - & - & - & - & 2.7 & 5 & 2.7 & 5 & 2.7 & 5 & 2.7 & 5 & 2.7 & 5 & 2.7 & 5 \\
\hline 12 & 2 & 4 & 3 & 5 & 2 & 4 & 2.7 & 5 & 2.7 & 5 & 2.7 & 5 & 2.7 & 5 & 2.7 & 5 & 2.7 & 5 \\
\hline 13 & - & - & - & - & - & - & 3.3 & 6 & 3.3 & 6 & 3.3 & 6 & 3.3 & 6 & 3.3 & 6 & 3.3 & 6 \\
\hline 14 & - & - & - & - & - & - & 3.1 & 6 & 3.1 & 6 & 3.1 & 6 & 3.1 & 6 & 3.1 & 6 & 3.1 & 6 \\
\hline 15 & 2 & 4 & 2 & 4 & 2 & 4 & 3.1 & 6 & 3.1 & 6 & 3.1 & 6 & 3.1 & 6 & 3.1 & 6 & 3.1 & 6 \\
\hline 16 & 2 & 4 & 2 & 4 & 3 & 5 & 2 & 4 & 2 & 4 & 2 & 4 & 2 & 4 & 2 & 4 & 2 & 4 \\
\hline
\end{tabular}


Table 8. A comparison of the fitness values using three proposed optimization techniques, with and without the hybrid WE/PEMFC system for the SOFs in year 2022 without and with considering the SFs.

\begin{tabular}{|c|c|c|c|c|c|c|c|}
\hline \multirow{3}{*}{ Items } & \multirow{3}{*}{$\begin{array}{c}\text { Without Inserting } \\
\text { the Hybrid } \\
\text { WE/PEMFC } \\
\text { System }\end{array}$} & \multicolumn{6}{|c|}{ With Inserting the Hybrid WE/PEMFC System } \\
\hline & & \multicolumn{2}{|c|}{ BCSA } & \multicolumn{2}{|c|}{ DJA } & \multicolumn{2}{|c|}{ BPSO } \\
\hline & & $\begin{array}{l}\text { Without } \\
\text { SFs }\end{array}$ & With SFs & $\begin{array}{c}\text { Without } \\
\text { SFs }\end{array}$ & With SFs & $\begin{array}{c}\text { Without } \\
\text { SFs }\end{array}$ & With SFs \\
\hline$F_{1}(\%)$ & 34.13 & 9.45 & 0.89 & 8.51 & 0.82 & 9.73 & 1.8 \\
\hline$F_{2}(\%)$ & 100 & 22.8 & 20.91 & 22.96 & 20.73 & 24.47 & 20.91 \\
\hline$F_{3}(\%)$ & 100 & 22.88 & 20.68 & 22.21 & 20.45 & 23.82 & 20.68 \\
\hline $\begin{array}{c}\text { Voltage } \\
\text { Improvement (\%) }\end{array}$ & - & 72.3 & 97.3 & 75 & 97.5 & 71.5 & 94.7 \\
\hline $\begin{array}{c}\text { Active Power } \\
\text { Losses Saving (\%) }\end{array}$ & - & 77.2 & 79.09 & 77 & 79.27 & 75.5 & 79.09 \\
\hline $\begin{array}{l}\text { Reactive Power } \\
\text { Losses Saving (\%) }\end{array}$ & - & 77.12 & 79.32 & 77.8 & 79.55 & 76 & 79.32 \\
\hline
\end{tabular}

DJA when considering the SFs that improves the bus voltage about $97.5 \%$, then, BCSA improves the bus voltage by $97.3 \%$, finally BPSO technique improves the bus voltage by $94.7 \%$. There is a clear improving in the value of $F_{1}$ when considering the effect of the SFs as $F_{1}$ is increased from $75 \%$ to $97.5 \%$ using DJA. Figure 6 and Figure 7 show the improvement in voltage profile using the three proposed optimization techniques without and with considering the SFs for $F_{1}$ as SOF, respectively.

\subsubsection{Minimizing of $F_{2}$ as a SOF}

Table 8 illustrates the saving in ALI without and with considering the SFs. From this Table, the best technique without considering the SFs is BCSA that gives the highest saving in active power losses (APLs) by $77.2 \%$, then, DJA gives saving in APLs by $77 \%$, finally BPSO technique gives saving in APLs of about $75.5 \%$. Also, the best technique when considering the SFs is DJA that gives the highest saving in APLs by $79.27 \%$, then, both BCSA and BPSO technique that give the same saving in APLs about $79.09 \%$. There is a significant improvement in the value of $F_{2}$ when considering the SFs that the saving in APLs is increased from $77 \%$ to 79.27 using DJA.

\subsubsection{Minimizing of $F_{3}$ as a SOF}

Table 8 illustrates the saving in $F_{3}$ without and with considering the SFs using the three proposed optimization techniques, the best technique without considering the SFs is DJA that gives the highest saving in reactive power losses (RPLs) by $77.8 \%$ then, BCSA saves the RPLs by $77.12 \%$, finally BPSO technique saves the RPLs by $76 \%$. Also, the best technique, when considering the SFs, is DJA that gives the highest saving in RPLs by $79.55 \%$, then, both BCSA and BPSO give the same saving in RPLs by $79.32 \%$. There is a significant improving 


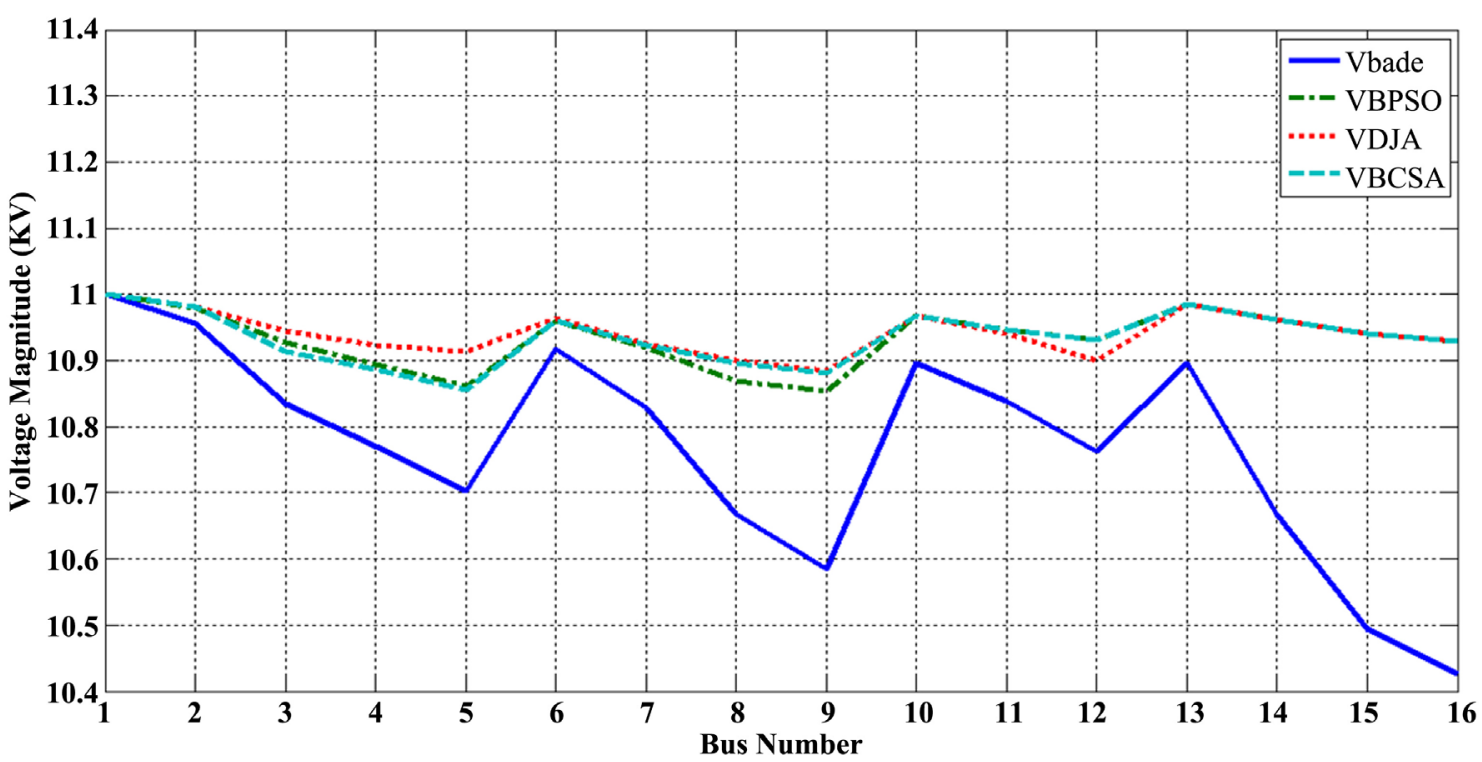

Figure 6. Voltage improvement using the three optimization techniques without considering the SFs in year 2022 using $F_{1}$ as $S O F$.

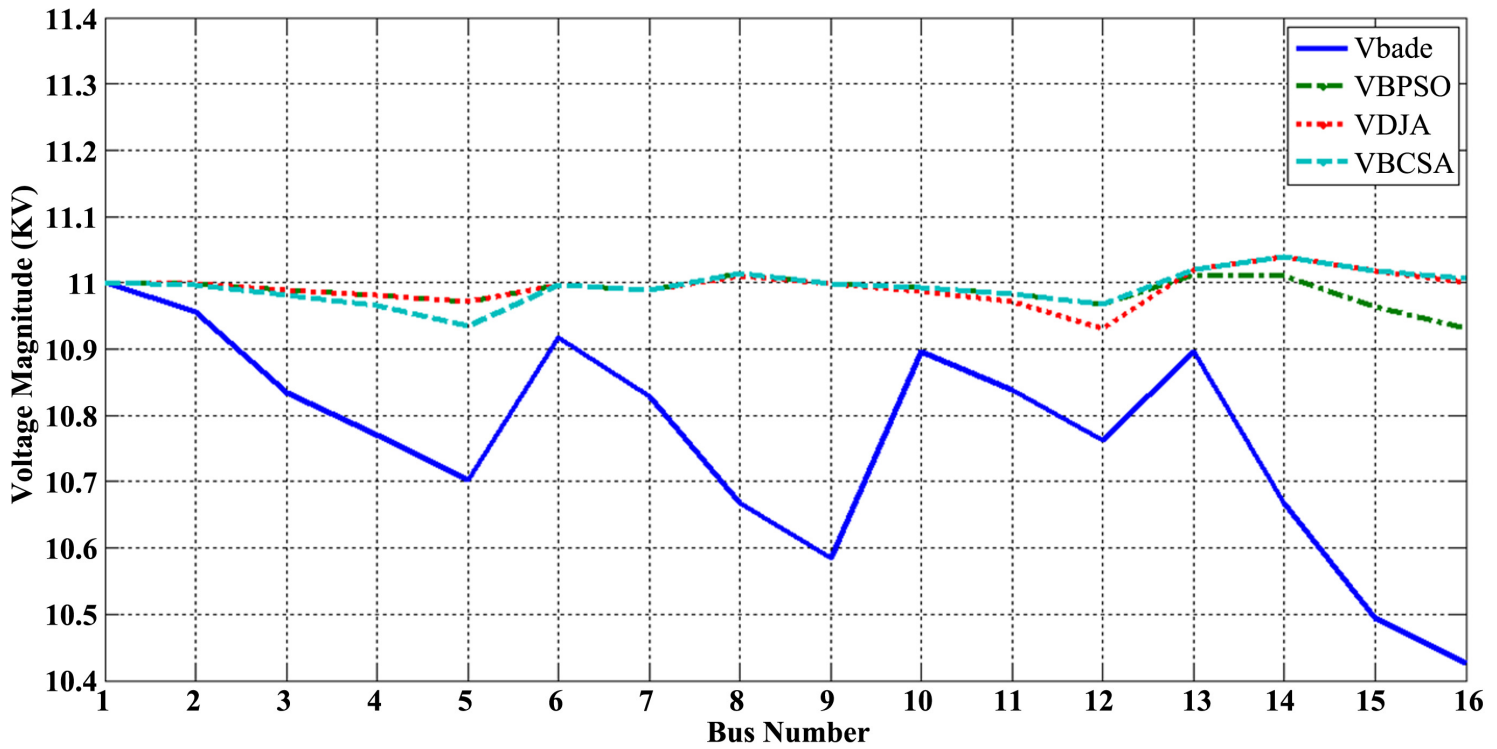

Figure 7. Voltage improvement using the three optimization techniques with considering the SFs in year 2022 using $F_{1}$ as $S O F$.

in the value of $\mathrm{F}_{3}$ after taking the SFs into consideration which the saving in RPLs is increased from $77.8 \%$ to $79.55 \%$ using DJA.

\subsubsection{Minimizing of MOF}

MOF are dependent on the values of WFs, which takes the value of $W_{1}$ as 0.5 to consider the voltage improvement is the first priority, while, the values of $W_{2}$ and $W_{3}$ take different values between [ 0 to 0.5 by step 0.05]. However, the values of $W_{2}$ and $W_{3}$ have taken as 0.45 and 0.05 , respectively, to optimize the MOF using both BCSA and BPSO technique without and with considering the SFs. 
While, $W_{2}$ and $W_{3}$ are taken as 0.05 and 0.45 , respectively, to optimize the MOF using DJA without and with considering the SFs. Table 9 shows the sitting and corresponding number of DGs using BCSA, DJA and BPSO technique using MOF without and with considering the SFs. A comparison of the fitness value using three proposed optimization techniques, with and without the hybrid WE/ PEMFC system using the MOF without and with considering SFs is shown in Table 10. From Table 10, DJA is the best technique without considering the SFs that minimizes the MOF from $67.07 \%$ (without inserting the hybrid system) to $18.07 \%$, (after inserting the hybrid system), reduces the TAPLs from 1.2348 MW to $0.313 \mathrm{MW}$, and, reduces the TRPLs from 1.544 MVAR to 0.3812 MVAR. Also, DJA is the best technique with considering the SFs that minimizes the MOF from $67.07 \%$ (without inserting the hybrid system) to $17.22 \%$ (after inserting the hybrid system) reduces the TAPLs from 1.2348 MW to $0.2601 \mathrm{MW}$, and reduces the TRPLs from 1.5421 MVAR to 0.3231 MVAR. There is a significant minimization in the value of MOF with considering the effect of SFs, however, MOF is reduced from $18.07 \%$ to $17.22 \%$ using DJA.

Figure 8 and Figure 9 show the improvement in voltage profile using the three proposed optimization techniques without and with the effect of SFs when considering the MOF in year 2022.

Table 9. Sitting, sizing (S) in MW and corresponding number of DGs (N) using the three proposed optimization techniques in year 2022 using $M O F$ without and with considering SFs.

\begin{tabular}{|c|c|c|c|c|c|c|c|c|c|c|c|c|}
\hline \multirow{3}{*}{ Bus. No } & \multicolumn{4}{|c|}{ BCSA } & \multicolumn{4}{|c|}{ DJA } & \multicolumn{4}{|c|}{ BPSO } \\
\hline & \multicolumn{2}{|c|}{ Without SFs } & \multicolumn{2}{|c|}{ With SFs } & \multicolumn{2}{|c|}{ Without SFs } & \multicolumn{2}{|c|}{ With SFs } & \multicolumn{2}{|c|}{ Without SFs } & \multicolumn{2}{|c|}{ With SFs } \\
\hline & S & $\mathrm{N}$ & S & $\mathrm{N}$ & S & $\mathrm{N}$ & S & $\mathrm{N}$ & S & $\mathrm{N}$ & S & $\mathrm{N}$ \\
\hline 2 & 2 & 4 & 2.9 & 5 & 7 & 12 & 2.9 & 5 & 4 & 7 & 2.9 & 5 \\
\hline 3 & 6 & 10 & 2.9 & 5 & 1 & 2 & 2.9 & 5 & 6 & 10 & 2.9 & 5 \\
\hline 4 & 2 & 4 & 2.7 & 5 & 2 & 4 & 2.7 & 5 & 2 & 4 & 2 & 4 \\
\hline 5 & 4 & 7 & 2.7 & 5 & 2 & 4 & 2 & 4 & 4 & 7 & 2.7 & 5 \\
\hline 6 & 7 & 12 & 3 & 5 & 7 & 12 & 1 & 2 & 5 & 9 & 3 & 5 \\
\hline 7 & 4 & 7 & 3.2 & 6 & 4.9 & 9 & 3.2 & 6 & 2 & 4 & 3.2 & 6 \\
\hline 8 & 2 & 4 & 3.3 & 6 & 2 & 4 & 3.3 & 6 & 5 & 9 & 3.3 & 6 \\
\hline 9 & 2 & 4 & 3.2 & 6 & 2 & 4 & 3.2 & 6 & 3 & 5 & 3.2 & 6 \\
\hline 10 & 2 & 4 & 2.9 & 5 & 2 & 4 & 2.9 & 5 & 3 & 5 & 2.9 & 5 \\
\hline 11 & 2 & 4 & 2 & 4 & 2 & 4 & 2.7 & 5 & 3 & 5 & 2.7 & 5 \\
\hline 12 & 3 & 5 & 2 & 4 & 4.9 & 9 & 2.7 & 5 & 2 & 4 & 3 & 5 \\
\hline 13 & 4 & 7 & 3.3 & 6 & 4.9 & 9 & 3.3 & 6 & 4 & 7 & 3.3 & 6 \\
\hline 14 & 3 & 5 & 3.1 & 6 & 2 & 4 & 3.1 & 6 & 2 & 4 & 3.1 & 6 \\
\hline 15 & 3 & 5 & 3.1 & 6 & 2 & 4 & 3.1 & 6 & 3 & 5 & 3.1 & 6 \\
\hline 16 & 3 & 5 & 2 & 4 & 2 & 4 & 2 & 4 & 2 & 4 & 2 & 4 \\
\hline
\end{tabular}


Table 10. A comparison of the fitness value using three proposed optimization techniques, with and without the hybrid WE/PEMFC system using the MOF in year 2022 without and with considering SFs.

\begin{tabular}{|c|c|c|c|c|c|c|c|}
\hline \multirow{3}{*}{ Items } & \multirow{3}{*}{$\begin{array}{c}\text { Without Inserting } \\
\text { the Hybrid } \\
\text { WE/PEMFC } \\
\text { System }\end{array}$} & \multicolumn{6}{|c|}{ With Inserting the Hybrid WE/PEMFC System } \\
\hline & & \multicolumn{2}{|c|}{ BCSA } & \multicolumn{2}{|c|}{ DJA } & \multicolumn{2}{|c|}{ BPSO } \\
\hline & & $\begin{array}{c}\text { Without } \\
\text { SFs }\end{array}$ & With SFs & $\begin{array}{c}\text { Without } \\
\text { SFs }\end{array}$ & With SFs & $\begin{array}{c}\text { Without } \\
\text { SFs }\end{array}$ & With SFs \\
\hline MOF (\%) & 67.07 & 19.02 & 17.37 & 18.07 & 17.22 & 20.31 & 17.32 \\
\hline TAPLs (MW) & 1.2348 & 0.2817 & 0.2612 & 0.3109 & 0.2601 & 0.313 & 0.2609 \\
\hline TRPLs (MVAR) & 1.5421 & 0.3529 & 0.3255 & 0.3892 & 0.3231 & 0.3812 & 0.3249 \\
\hline
\end{tabular}

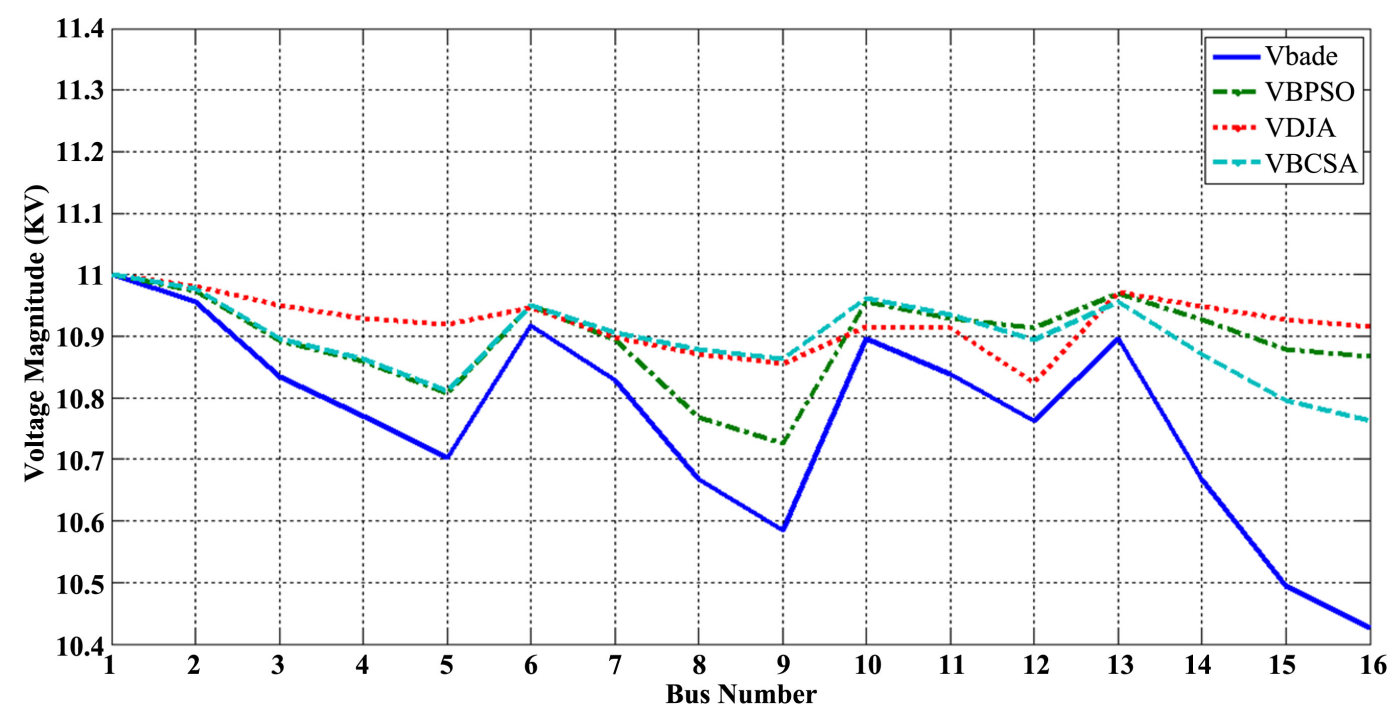

Figure 8. Voltage improvement using the three optimization techniques without considering the SFs in year 2022 using $M O F$.

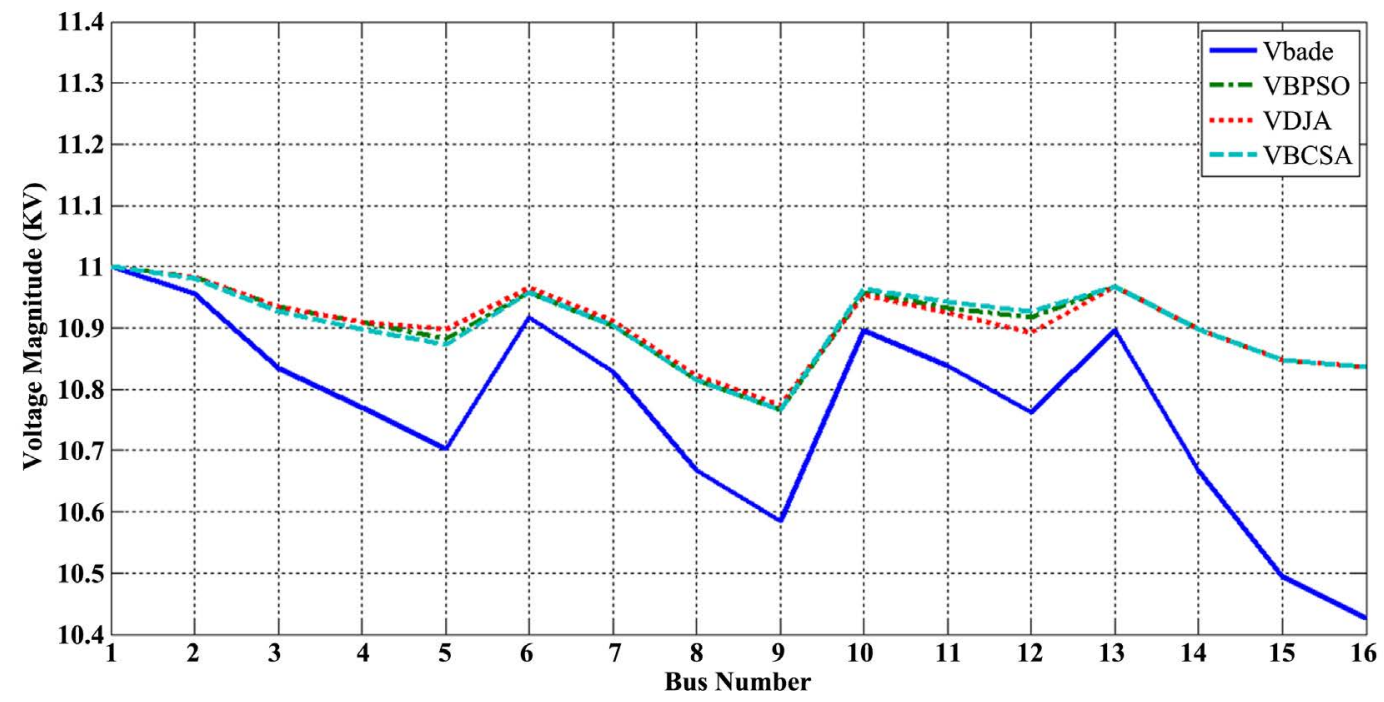

Figure 9. Voltage improvement using the three optimization techniques with considering the SFs in year 2022 using MOF. 


\section{Conclusion}

In this paper, a proposed hybrid WE/PEMFC system includes WTs and PEMFC has been efficiently presented. Proposed economical and generation models of $3000 \mathrm{~kW}$-WT had been presented. Also, the economics of both wind energy and the PEMFC system had been discussed in year 2022. The BFS method has been used for the load flow calculation. A two-stage procedure has been introduced to allocate a hybrid WE/PEMFC system in the EDS for Mersi-Matrough City. In the first stage, the sensitivities analysis using three SFs have been presented to select the candidate buses for locating the hybrid system. While, in the second stage, the BCSA, DJA and BPSO techniques have been investigated to find the optimal allocation of the hybrid system considering the improvement of voltage profile and the minimization of both APLs and RPLs as objective functions, while system constraints are fully satisfied. Best optimization results have been obtained using DJA compared to BCSA and BPSO technique. Also, the proposed procedure using DJA considering $M O F$ gives the best results in compared with the other two techniques. By considering the effect of SFs, the improvement in the value of the $\mathrm{F}_{1}$ is increased; however, the hybrid system is located at only 5 candidate system buses instead of the 16 buses. So, these SFs decrease the search space for optimization techniques and improve the voltage profile. Also, there are more significant saving in both $\mathrm{F}_{2}$ and $\mathrm{F}_{3}$ when the hybrid system are located at the candidate buses. The proposed procedure represents a potential tool to improve bus voltage magnitude, reduce both APLs and RPLs and helps their operators in smart grid environment.

\section{Conflicts of Interest}

The authors declare no conflicts of interest regarding the publication of this paper.

\section{References}

[1] Hoff, T.E., Wenger, H.J. and Framer, B.K. (1996) Distributed Generation an Alternative to Electric Utility Investments in System Capacity. Energy Policy, 24, 137-147. https://doi.org/10.1016/0301-4215(95)00152-2

[2] Allam, S.M., EL-Zeftawy, A.A. and Shehata, N.K. (2012) Operation of Electrical Utility with Application in Egypt. 8th International Conference on Electrical Engineering, 29-31 May 2012. https://doi.org/10.21608/iceeng.2012.30816

[3] Lasseter, R.H. (1998) Control of Distributed Resources. Proceedings: Bulk Power Systems Dynamics and Control IV, Restructuring, Athens, 23-28 August 1998, 323 329.

[4] Brown, R.E. and Freeman, L.A.A. (2001) Analyzing the Reliability Impact on Distributed Generation. IEEE Power Engineering Society Summer Meeting, Vol. 2, 1013 1018 .

[5] Brown, R.E., Pan, J., Feng, X. and Koutlev, K. (2001) Sitting Distributed Generation to Defer T\&D Expansion. Transmission and Distribution Conference and Exposition, Vol. 2, 622-627.

[6] New and Renewable Energy Authority (1996) Wind Energy in Egypt Strategy Pro- 
gram and Project. Report.

[7] Mortensen, N.G., Said, U. and Bedger, J. (2006) Wind Atlas for Egypt. Riso National Laboratory, Roskilde, New and Renewable Energy Authority, Cairo.

[8] Yang, W.-J. and Aydin, O. (2001) Wind Energy-Hydrogen Storage Hybrid Power Generation. International Journal of Energy Research, 25, 449-463. https://doi.org/10.1002/er.696

[9] Luo, X., Wang, J., Dooner, M. and Clarke, J. (2015) Overview of Current Development in Electrical Energy Storage Technologies and the Application Potential in Power System Operation. Applied Energy Journal, 137, 511-536. https://doi.org/10.1016/j.apenergy.2014.09.081

[10] Woodbank.com. Woodbank Communications Ltd., Chester.

[11] Azmy, A.M. and Imam, S.M. (2015) Sizing and Economic Analysis of Standalone PEM Fuel Cell Systems for Residential Utilization. Recent Innovations in Mechatronics, Vol. 2. https://doi.org/10.17667/riim.2015.1-2/17.

[12] (2004) Renewable and Efficient Electric Power Systems. John Wiley \& Sons, Hoboken.

[13] Wang, Y., Diaz, D.F.R., Chen, K.S., Wang, Z. and Adroher, X.C. (2020) Materials, Technological Status, and Fundamentals of PEM Fuel Cells: A Review. Materials Today, 32, 178-203. https://doi.org/10.1016/j.mattod.2019.06.005

[14] Islam, S. and Belmans, R. (2004) Grid Independent Photovoltaic Fuel-Cell Hybrid System: Optimal Design and Control Strategy. 19th European Photovoltaic Solar Energy, 3311-3314.

[15] Godwin, U.O., Callistus, O.C. and Paul, I.J. (2013) A Power Estimation Model for Wind-Hydrogen-Fuel Cell-Inverter Hybrid Power Generation System. International Journal of Advanced Research in Electrical, Electronics and Instrumentation Engineering, 2, 2474-2485.

[16] Kamal, T. and Hassan, S.Z. (2016) Energy Management and Simulation of Photovoltaic/Hydrogen/Battery Hybrid Power System. ASTES Journal, 1, 11-18. https://doi.org/10.25046/aj010203

[17] Das, D., Esmaili, R., Xu, L. and Nichols, D. (2005) An Optimal Design of a Grid Connected Hybrid Wind/Photovoltaic/Fuel Cell System for Distributed Energy Production. 31st Annual Conference of IEEE Industrial Electronic Society, Raleigh, 6-10 November 2005. https://doi.org/10.1109/IECON.2005.1569298

[18] Zakaria, E.M., Arafa, S.H., Nashed, M.F. and Ramadan, S.G. (2020) Fuzzy Logic Control Management with Stand Alone Photovoltaic-Fuel Cell System. ASTES Journal, 5, 424-430. https://doi.org/10.25046/aj050154

[19] Shao, Z. and Lo, K.L. (2017) A Case Study to Determine Optimal Capacity of a Stand-Alone Wind/PV/Battery System. Energy and Power Engineering Journal, 9 , 300-307. https://doi.org/10.4236/epe.2017.94B035

[20] Traore, A., Elgothamy, H. and Zohdy, M.A. (2018) Optimal Sizing of Solar/Wind Hybrid Off-Grid Microgrids Using an Enhanced Genetic Algorithm. Journal of Power and Energy Engineering, 6, 64-77. https://doi.org/10.4236/jpee.2018.65004

[21] Crebbin, G. and Yang, X. (2016) Optimal Generator Placement in a Distributed Network. ENG470, Murdoch University, Murdoch.

[22] Kotob, M.F., Shebl, K.M., El Khazendar, M. and El Husseiny, A. (2010) Genetic Algorithm for Optimum Sitting and Sizing of Distributed Generation. MEPCON 10 , Cairo, 19-21 December 2010.

[23] Das, P. (2015) Optimal Sizing and Placement of Distributed Generation in A Radial 
Distribution System Using Loss Sensitivity Factor and Firefly Algorithm. Intentional Journal of Scientific Research and Management, 3, 2611-2618.

[24] Becerra, J.E.C. and Riano, H.E.H. (2015) Distributed Generation Placement in Radial Distribution Networks Using a Bat-Inspired Algorithm. Dyna, 82, 60-67. https://doi.org/10.15446/dyna.v82n192.48573

[25] Wang, L. and Singh, C. (2008) Reliability-Constrained Optimum Placement of Reclosers and Distributed Generators Distribution Networks Using Ant Colony System Algorithm. IEEE Transactions on Systems, Man, and Cybernetics Part C: Application and Reviews, 38, 757-764. https://doi.org/10.1109/TSMCC.2008.2001573

[26] Sutthibun, T. and Bhasaputra, P. (2010) Multi-Objective Optimal Distributed Generation Placement Using Simulated Annealing. Proceedings ECTI-CON International Conference on Electrical Engineering/ Electronics Computer Telecommunications and Information Technology, 810-813.

[27] Aly, A.I., Hegazy, Y.G. and Alsharkawy, M.A. (2010) A Simulated Annealing Algorithm for Multi-Objective Distributed Generation Planning. Proceedings IEEE Power and Energy Society General Meeting, Providence, 25-29 July 2010, 1-7. https://doi.org/10.1109/PES.2010.5589950

[28] Ghadimi, N. and Ghadimi, R. (2012) Optimal Allocation of Distributed Generation and Capacitor Banks in order to Loss Reduction in Reconfigured System. Research Journal of Applied Sciences Engineering and Technology, 4, 1099-1104.

[29] El-Ela, A.A.A., El-Sehiemy, R.A., Kinawy, A.M. and Mouwafi, M.T. (2016) Optimal Capacitor Placement in Distribution Systems for Power Loss Reduction and Voltage Profile Improvement. IET Generation, Transmission \& Distribution, 10, 1209-1221. https://doi.org/10.1049/iet-gtd.2015.0799

[30] Rana, A.D., Darji, J. and Pandya, M. (2014) Backward/Forward Sweep Load Flow Algorithm for Radial Distribution Systems. International Journal for Scientific Research and Development, 2, 398-400.

[31] Sayed, G.I., Hassanien, A.E. and Azar, A.T. (2017) Feature Selection via a Novel Chaotic Crow Search Algorithm. Neural Computing and Applications, 31, 171-188.

[32] Askarzadeh, A. (2016) A Novel Metaheuristic Method for Solving Constrained Engineering Optimization Problems: Crow Search Algorithm. Computers and Structures, 169, 1-12. https://doi.org/10.1016/j.compstruc.2016.03.001

[33] Souza, R.C.T., Macedo, C.A., Coelho, L.S. and Pierezan, J. (2018) A V-Shaped Binary Crow Search Algorithm for Feature Selection. 2018 IEEE Congress on Evolutionary Computation, Rio de Janeiro, 8-13 July 2018.

[34] Rao, R.V. (2016) Jaya: Simple and New Optimization Algorithm for Solving Constrained and Unconstrained Optimization Problems. International Journal of Industrial Engineering Computations, 7, 19-34. https://doi.org/10.5267/j.ijiec.2015.8.004

[35] El-Ela, A.A.A., Allam, S.M. and Shehata, N.K. (2019) Optimal Allocation of a Hybrid Renewable Energy-Storage System for Supplying Egyptian Distribution Networks Using Discrete Jaya Algorithm. MEPCON21, Tanta, 19-21 December 2019. https://doi.org/10.1109/MEPCON47431.2019.9008204

[36] Kothari, D.P. and Dhillon, J.S. (2004) Power System Optimization. Prentice Hall, New Delhi.

[37] El-Ela, A.A.A., Allam, S.M. and Shehata, N.K. (2017) Assessment of Hybrid Renewable Energy with Energy Storage System for Supplying Distribution Networks in Egypt. MEPCON 19, Shibin el Kom, 19-21 December 2017. https://doi.org/10.1109/MEPCON.2017.8301365 
[38] Aly, G.E.M., El-Gharabawy, A.E. and El-Zeftawy, A.A. (2001) Optimizing the Operation of Wind Generators at the Installation Site. Proceedings of the 8th International Middle East Power Conference, MEPCON2001, Cairo, 29-31 December 2001, 951-955.

[39] http://www.americanenergyindependence.com/hydrogen.aspx

[40] Azmy, A.M. and Imam, S.M. (2015) Sizing and Economic Analysis of Standalone PEM Fuel Residential Utilization. Recent Innovations in Mechatronics, Debrecen, Volume 2. https://doi.org/10.17667/riim.2015.1-2/17.

[41] Azmy, A.M., Imam, S.M., Rashad, E. and Husi, G. (2014) Sizing and Economic Analysis of Hybrid PV/PEMFC Systems for Remote Areas Residential Utilization. MEPCON 14, Cairo, 13-15 December 2014.

[42] El-Ela, A.A.A., Allam, S.M. and Said Ahmed, M.M. (2016) Reliable Operating Assessment for Hybrid PV/Wind Energy Generation System to Supply New City in Egypt. 18th International Middle East Power Systems Conference, MEPCON18, Helwan, 27-29 December 2016.

[43] http://www.Fuelcellstore.com

[44] Wiser, R., Bolinger, M., Hoen, B., Millstein, D., Rand, J. and Barbose, G. (2020) Wind Energy Technology Data Update: 2020 Edition. Lawrence Berkeley National Laboratory, Washington DC.

[45] http://www.mahytec.com 


\section{Appendix}

The key features of the QLC PEM electrolyzer used in this paper is illustrated in Table A1. While, the specification of type four hydrogen tank is illustrated in Table A2.

Table A1. Key features of QLC PEM electrolyzer cell stack [43].

\begin{tabular}{cccccccc}
\hline Model & QLC-60 & QLC-120 & QLC-180 & QLC-240 & QLC-300 & QLC-500 & QLC-1000 \\
\hline Cells & 1 & 2 & 3 & 4 & 1 & 2 & 4 \\
Stack Diameter (mm) & 85 & 85 & 85 & 85 & 138 & 138 & 138 \\
$\begin{array}{c}\text { H2 Flow Rate } \\
(\mathrm{mL} / \mathrm{min})\end{array}$ & $0-60$ & $0-120$ & $0-180$ & $0-240$ & $0-300$ & $0-500$ & $0-1000$ \\
Price (\$) & 607 & 881 & 1162 & 1320 & 1487 & 1934 & 3591 \\
\hline
\end{tabular}

Table A2. Specification of type four hydrogen tank 500 bar-200L [45].

\begin{tabular}{cc}
\hline Items & $\mathrm{H}_{2}$ tank 500 bar-200L \\
\hline Mass of $\mathrm{H}_{2}$ Stored at 500 bar and $15^{\circ} \mathrm{C}(\mathrm{kg})$ & 6.5 \\
Temperature of Use $\left({ }^{\circ} \mathrm{C}\right)$ & From $-40{ }^{\circ} \mathrm{C} \rightarrow 65^{\circ} \mathrm{C}$ \\
Maximum Press (bar) & 500 \\
Inner Volume (Litre) & 200 \\
Mass of Empty Tank (kg) & 188 \\
External Dimensions (cm) & $49 \times 223$ \\
H Tank Material & Polymer liner reinforced with composite material \\
Life Time (year) & 10 \\
\hline
\end{tabular}

